\title{
KAJIAN SISTEMATIK: STRATEGI PEMBELAJARAN KLINIK DI SETTING RAWAT JALAN
}

\author{
Ova Emilia \\ Fakultas Kedokteran Universitas Gadjah Mada
}

\begin{abstract}
Background: Clinical education in outpatient settings acknowledged as a challange for clinical instructors, which they had to provide efficient and qualified service to the patients while also including educational components that significantly handful for clinical students. We recognized many learning strategies to encounter those challanges, but only few of them that had been evaluated. This systematic review were provided to compare various clinical learning strategies which are useful in outpatient setting.
\end{abstract}

Method: Literature searching has done according PubMed database that related in topics such the impact of clinical education in outpatient setting on learning, outcome, and also efficiency of the outpatient clinics. There were no boundary setting that cone in this systematic review.

Results: There were two learning strategy: "One Minute Perceptor" (OMP) and SNAPPS has been showed to be effective in increasing educational-learning process and service outcome. Another two strategies such as "Aunt Minnie" pattern recognition and "Active Demonstration" were also promising but hadn't been sufficiently studied. There weren't any of those strategies showed their impact in outpatient clinic setting efficiency.

Conclusion: OMP and SNAPPS may be used for clinical mentoring in outpatient settings to increase learning process and learning outcome, while pattern recognition and activated demonstration hadn't show any promising evidence.

Keywords: one-minute perceptor, SNAPPS, clinical education, outpatient clinics setting

\section{ABSTRAK}

Latar belakang: Pendidikan klinik di rawat jalan merupakan tantangan pada pembimbing yaitu tetap memberikan pelayanan yang berkualitas dan efisien serta memasukkan komponen pendidikan yang bermakna bagi mahasiswa. Banyak strategi pembelajaran yang diusulkan untuk menghadapi tantangan tersebut, tetapi hanya ada beberapa strategi saja yang telah dievaluasi dampaknya baik untuk pendidikan ataupun pelayanan. Kajian sistematik ini ditujukan untuk menilai berbagai strategi pembelajaran klinik yang dapat dipakai di poliklinik.

Metode: Dilakukan penelusuran literatur melalui data base PubMed tentang dampak pembelajaran klinik di poliklinik dan pengaruhnya pada strategi pembelajaran, luaran dan efisiensi poliklinik. Tidak dilakukan pembatasan rancangan studi yang diambil dalam kajian ini.

Hasil: Dua strategi pembelajaran yaitu "one-minute preceptor" (OMP) dan "SNAPPS," menunjukkan dapat meningkatkan proses pendidikan dan luaran pelayanan. Dua strategi lainnya, "Aunt Minnie" pattern recognition dan "activated demonstration," cukup menjanjikan namun belum banyak diteliti. Tidak ada satupun dari strategi tersebut menunjukkan pengaruhnya pada efisiensi rawat jalan.

Kesimpulan: Strategi OMP dan SNAPPS dapat dipakai dalam proses pembimbingan di poliklinik untuk meningkatkan proses pendidikan dan luarannya, sedangkan pattern recognition dan activated demonstration belum menunjukkan bukti yang menjanjikan.

Kata kunci: one-minute perceptor, SNAPPS, pendidikan klinik, rawat jalan

korespondensi: ovaemilia@gmail.com 


\section{PENDAHULUAN}

Pendidikan klinik di rumah sakit merupakan tantangan dalam pendidikan dokter dan residen khusunya karena harus mengharmonisasikan antara pelayanan kesehatan berkualitas, efisiensi dan pendidikan yang bermakna bagi peserta didik. Banyak literatur mengkaji hambatan umum pendidikan klinik yang efektif, termasuk di dalamnya adalah hambatan waktu, dukungan finansial, kurangnya akses dokter spesialis dan kurangnya ruang serta sumber daya pendidikan. ${ }^{1}$ Lebih lanjut lagi penelitian menunjukkan bahwa dokter yang aktif membimbing mahasiswa biasanya akan menghabiskan banyak waktu untuk pendidikan sehingga tentunya akan melayani laebih sedikit pasien dan berkurangnya pendapatan. ${ }^{2}$ Dalam konteks pendidikan klinik di rawat jalan, dokter biasanya memilih pasien dengan memperhatikan 3 faktor yaitu pengaruh pendidikan pada hubungan dokter pasien, manfaat pendidikan bagi mahasiswa dan pertimbangan waktu dan efisensi. $^{3}$

Dampak pendidikan klinik pada hubungan dokter pasien dapat dipengaruhi oleh apakah pasien datang untuk follow up, apakah ingin ditangani dokter tertentu atau pasien baru yang memungkinkan mahasiswa belajar kasus sejak awal. Yang terbaik dari aspek mahasiswa adalah memperoleh pasien baru dengan masalah yang baru atau kesempatan untuk mengikuti senior untuk memaksimalkan paparan keterampilan diagnosis dan manajemen. Selain itu efisiensi proses belajar dipengaruhi oleh jumlah pasien yang ditangani dan keseimbangan antara menangani follow up pasien vs pasien yang baru dan belum terdiagnosis.

\section{METODE}

Banyak model ataupun strategi pembelajaran klinik yang dipaparkan dalam literatur pendidikan kedokteran. Di dalam kajian sistematik ini dikaji empat strategi pendidikan klinik dan bukti dampaknya pada luaran pendidikan ataupun efisiensi poli rawat jalan. Literatur ditelusur menggunakan mesin pencari PubMed dengan kata kunci "medical student" dan "precepting".

\section{HASIL DAN PEMBAHASAN}

One minute preceptor (OMP) - pendidikan menggunakan 5 langkah microskills

Strategi OMP pertamakali dikenalkan di awal tahun 1990an, merekomendasikan 5 langkah atau microskills untuk memberikan struktur pembimbingan klinik. Langkah pertama, membuat komitmen, adalah langkah memastikan tujuan mahasiswa untuk pembimbingan. Pada tahap ini pembimbing mendorong mahasiswa memproses dan mensintesis informasi yang diperoleh dari pasien. Pertanyaan yang diberikan seperti "apa yang mau dilakukan?" atau "bila saya tidak ada apa yang akan kamu lakukan pada pasien?". Langkah kedua, menggali bukti yang mendukung, dengan menggunakan pertanyaan seperti "faktor apa yang kamu pertimbangkan untuk mengusulkan tindakan tsb? Atau "adakah pilihan lain yang ingin kamu pertimbangkan atau kamu buang?". Penekanannya di sini seorang pembimbing harus memahami tingkat pengetahuan, proses analisis dan materi belajar yang perlu dipelajari lagi. Langkah ke tiga, pembimbing memberikan "feedback positif" terhadap hal-hal yang sudah dikuasai mahasiswa. Langkah ini paling sering dilewatkan dalam pembimbingan, padahal literatur menunjukkan bahwa pemberian feedback positif akan meningkatkan motivasi dan rasa percaya diri mahasiswa. Langkah ke empat, memberikan feedback terhadap hal-hal yang perlu diperbaiki oleh mahasiswa misalnya "kelengkapan informasi yang dikumpulkan, usulan pemeriksaan penunjang" dan mendiskusikan cara memperbaikinya. Langkah ke lima, pembimbing memberikan "penjelasan singkat ataupun tips-tips" ataupun saran terkait pemahaman dan manajemen kasus. ${ }^{4}$

Sebuah penelitian membandingkan model OMP dengan model tradisional terhadap 116 pembimbing di rotasi penyakit dalam dan kedokteran keluarga pada 7 program pelatihan staf menggunakan video. Pembimbing yang melihat OMP akan lebih baik dalam mendiagnosis masalah pasien dibandingkan pembimbing yang menyaksikan model pembimbingan tradisional. Pembimbing yang menyaksikan video model OMP juga menilai kemampuan mahasiswa lebih tinggi pada anamnesis dan pemeriksaan pasien, presentasi, penalaran 
klinik dan pengetahuan. Selain itu pembimbing tersebut juga menilai dirinya lebih percaya diri dalam mengevaluasi kemampuan mahasiswa. ${ }^{5}$ Hal lain yang dinilai positif adalah pembimbing yang menyaksikan video model OMP lebih menekankan pembelajaran terkait penyakit yang lebih spesifik juga mendorong digunakannya penalaran yang lebih tinggi. ${ }^{6}$ Pada penelitian lain oleh peneliti yang sama, emnunjukkan bahwa mahasiswa tahun ke tiga dan ke empat yang menggunakan model OMP merasakan proses yang lebih efektif dibandingan pendidikan tradisional. ${ }^{?}$

Pada penelitian terhadap residen yang diberi sesi pelatihan OMP selama 1 jam, menunjukkan bahwa residen merasa lebih berkomitmen, memperoleh umpan balik dan memotivasi belajar lebih lanjut, walaupun keektifan pembelajaran secara keseluruhan tidak berbeda antara residen dengan pelatihan OMP dan tidak. ${ }^{8}$ Pada pelatihan terhadap staf setelah mengikuti seminar model OMP selama 90 menit, didapt peningkatan kualitas umpan balik yang spesifik. $^{9}$

\section{SNAPPS - pendidikan peserta aktif}

Strategi SNAPPS dikembangkan berdasarkan teori pembelajaran kognitif dan reflektif. Pendekatan ini menekankan belajar aktif dan mendudukan proses bimbingan sebagai pengalaman aktif. Istilah SNAPPS merupakan akronim 6 langkah proses yaitu Summarize, Narrow the DD, Analyse, Probe, Plan, dan Select learning issue. ${ }^{10}$ Pertama mahasiswa diminta merumuskan, selama 3 menit atau kurang, anamnesis dan pemeriksaan fisik. Kedua, mahasiswa diminta mempersempit diagnosis diferensial atau intervensi yang mungkin menjadi 2-3 yang paling relevan/mungkin. Ketiga, Mahasiswa harus menganalisis DD atau intervensi dengan membandingkan dan membedakan melalui proses menjelaskan (memverbalkan) proses berfikirnya. Ke empat mahasiswa diminta menggali pengetahuan pembimbing dengan menanyakan hal-hal yang belum jelas. Fase ini memungkin pembimbing memahami proses berfikir dan landasan pengetahuan mahasiswa dan sekaligus memberikan umpanbalik dan informasi yang diperlukan. Kelima, merencanakan manajemen pasien, mahasiswa melakukan diskusi dengan pembimbing tentang rencana manajemen atau intervensi khusus dan menyempurnakannya dengan bantuan masukan dari pembimbing. Fase terakhir adalah mahasiswa memilih materi-materi baru yang perlu dipelajari lebih lanjut tentunya dengan bantuan pembimbing. ${ }^{10}$ Evaluasi SNAPPS menunjukkan bahwa mahasiswa yang dibimbing dengan SNAPPS dapat memberikan ringkasan kasus lebih rinci, kemudian mempresentasikan lebih banyak kemungkinan diagnosis dengan tingkat ketepatan diagnosis lebih tinggi. Mahasiswa yang memakai SNAPPS juga lebih baik dalam hal membandingkan hipotesis, menjelaskan ketidakpastian, mendiskusikan tentang manajemen dan mengidentifikasi topik yang harus dipelajari lebih lanjut. ${ }^{11}$

\section{"Aunt Minnie" - pentingnya Pattern recognition}

Sebagian besar metode pendidikan klinik memfokuskan pada diskusi penalaran kritik antara mahasiswa dan pembimbing dan eksplorasi ringkas pada pilihan diagnosis atau manajemen. Sebaliknya, pendekatan "Aunt Minnie" merupakan cara mendidik menggunakan pentingnya pattern recognition dalam praktek klinik. Jadi prinsipnya "bila wanita yang menyeberang jalan seperti Aunt Minnie dan berpakaian seperti Aunt Minnie, kemungkinan besar memang itu Aunt Minnie”. Pendekatan seperti itu adalah yang paling banyak dilakukan oleh pembimbing klinik khususnya di konteks rawat jalan. Salah satu pendekatan "Aunt Minnie" pattern recognition adalah: (1) mahasiswa mengevaluasi pasien dan mempresntasikan kepada pembimbing keluhan utama dan kemungkinan diagnosisnya, (2) mahasiswa menulis hasil temuannya dan pembimbing mengevaluasi pasien, (3) pembimbing mendiskusikan kasus dengan mahasiswa, (4) pembimbing mengkaji catatan medik dan menandatanganinya. ${ }^{12,13}$

Pattern recognition sudah banyak dipakai dalam pendidikan radiologi, masih belum banyak penerapannya dalam pendidikan lain bidang lain. Salah satu studi menunjukkan bahwa pattern recognition dapat dipakai untuk mengembangkan ujian akhir totasi bagi mahasiswa rotasi Bedah. ${ }^{14}$ Penelitian lain membandingkan pembelajaran penalaran klink untuk memberi kesempatan 
pada mahasiswa untuk menangani kasus tersebut. Penelitian menunjukkan bahwa instruksi pada mahasiswa untuk memakai pattern recognition dikombinasi dengan gambaran kasus yang dihadapi akan menghasilkan akurasi diagnostik yang lebih baik. ${ }^{15}$ Akhirnya penelitian lain juga menunjukkan bahwa mahasiswa yang menggunakan pattern recognition lebih cepat menguasai manajemen kasus dibandingkan mahasiswa yang hanya menggunakan metode interpretasi data. ${ }^{15}$ Meskipun penelitian di atas tidak berkaitan langsung dengan model "Aunt Minnie", tetapi menunjukkan bahwa peran pattern recognition dalam pendidikan kedokteran.

\section{Activated demonstration}

Proses pembelajaran pengetahuan dan berfikir analitik dapat diajarkan di ruang periksa atau bersama pembimbing melakukan pemeriksaan fisik atau intervensi prosedural yang memerlukan kehadiran pembimbing, demostrasi, supervisi dan umpanbalik. Activated demonstration adalah salah satu cara pembimbing untuk memaksimalkan nilai pendidikan demonstrasi dan memberikan mahasiswa pengalaman yang tidak pasif. Activated demonstration dimulai dengan menentukan tingkat pengetahuan mahasiswa dan tujuan belajar demonstrasi. Pembimbing kemudian memberikan bimbingan apa yang harus dilakukan selama demonstrasi kasus termasuk diskusi dan pemeriksaan pasien. Setelah demonstrasi keterampilan, pembimbing mendiskusikan topik belajar dengan mahasiswa dan menetapkan kesempatan belajar mahasiswa. Evaluasi terhadap pendekatan ini menunjukkan bahwa pembimbing membaik kemampuannya untuk memilih strategi mengajar yang individual dibutuhkan mahasiswa. ${ }^{16}$

Dampak pembelajaran terhadap efisiensi dan produktifikas dokter di rawat jalan telah banyak diketahui dan merupakan hal yang perlu diperhatikan oleh pembimbing klinik. Sejauh ini metode OMP dan SNAPPS yang telah banyak dinilai pengaruhnya terhadap kualitas pelayanan rawat jalan dan keduanya tidak dimaksudkan untuk memperpendek bimbingan klinik..$^{9110}$ Baik OMP dan SNAPPS dapat meningkatkan keterampilan klinik, penalaran klinik dan motivasi belajar mandiri. OMP dapat meningkatkan keterampilan membimbing dan dianjurkan sebagai model yang dapat dipakai oleh pembimbing klinik. SNAPPS memiliki keunggulan teoritik untuk memberi penekanan pada belajar mandiri, tetapi tidak ada perbandingan antara SNAPPS dan OMP terkait dengan pengaruhnya pada belajar mandiri. Beberapa penelitian yang diperlukan bidan pendidikan klinik adalah: Apakah OMP atau SNAPPS lebih mendorong belajar mandiri? Strategi apa yang dapat membantu efisiensi pembelajaran di rawat jalan? Bagaimana cara terbaik untuk menggunakan pattern recognition dan activated demonstration di dalam pendidikan klinik?

\section{KESIMPULAN}

Keempat model pembelajaran potensial untuk membantu meningkatkan keefektifan pembelajaran klinik di rawat jalan. OMP paling banyak diteliti dan menunjukkan pengaruh yang positif terhadap diagnosis masalah pasien selain juga menekankan pada pembelajaran penyakit tertentu. OMP juga memperbaiki kinerja pembimbing klinik dalam menarik mahasiswa berkonsultasi, memotivasi mahasiswa belajar manndiri dan memberikan umpan balik. Mahasiswa yang dibimbing dengan model OMP menunjukkan kemampuan anamnesis, pemeriksaan fisik, penalaran klinik dan pengetahuan dasar yang lebih baik. SNAPPS lebih sedikit diteliti, tetapi juga menunjukkan perannya dalam meningkatkan kemampuan presentasi, penalaran klinik dan belajar mandiri mahasiswa. Penelitian menunjukkan bahwa pattern recognition juga memiliki peran dalam pembelajaran dan menguji penalaran klinik mahasiswa. Kemudian pendekatan "Aunt Minnie" merupakan aplikasi pattern recognition pada pendidikan klinik, tetapi sejauh ini belum ada penelitian yang telah dipublikasikan mengevaluasi pendekatan ini. Model activated demonstration menjanjikan memperbaiki kemampuan pembimbing memilih strategi pembelajaran yang sesuai dengan kebutuhan mahasiswa, sehingga model ini juga perlu dievaluasi untuk melihat penggunaan dan manfaatnya.

\section{DAFTAR PUSTAKA}

1. DaRosa DA, Skeff K, Friedland JA, et al. Barriers to effective teaching. Acad Med. 2011;86(4):453-459. PubMed PMID: 21346500 
2. Levy BT, Gjerde CL, Albrecht LA. The effects of precepting on and the support desired by community-based preceptors in Iowa. Acad Med. 1997;72(5):382-384. PubMed PMID: 9159585.

3. Simon SR, Davis D, Peters AS, Skeff KM, Fletcher RH. How do precepting physi- cians select patients for teaching medical students in the ambulatory primary care setting? J Gen Intern Med. 2003;18(9):730-735. PubMed PMID: 12950482.

4. Neher JO, Stevens NG. The one-minute preceptor: shaping the teaching conver-sation. Fam Med. 2003;35(6):391-393. PubMed PMID: 12817861.

5. Aagaard E, Teherani A, Irby DM. Effectiveness of the one-minute preceptor model for diagnosing the patient and the learner: proof of concept. Acad Med. 2004;79(1):42-49. PubMed PMID: 14690996

6. Irby DM, Aagaard E, Teherani A. Teaching points identified by preceptors observing one-minute preceptor and traditional preceptor encounters. Acad Med.2004;79(1):50-55. PubMed PMID: 14690997.

7. Teherani A, O'Sullivan P, Aagaard EM, Morrison EH, Irby DM. Student perceptions of the one minute preceptor and traditional preceptor models. Med Teach. 2007;29(4):323-327.

8. Furney SL, Orsini AN, Orsetti KE, Stern DT, Gruppen LD, Irby DM. Teaching the one-minute preceptor. a randomized controlled trial. J Gen Intern Med.2001;16(9):620-624. PubMed PMID: 11556943.

9. Salerno SM, O'Malley PG, Pangaro LN, Wheeler GA, Moores LK, Jackson JL. Faculty development seminars based on the one- minute preceptor improve feed-back in the ambulatory setting. J Gen Intern Med. 2002;17(10):779-787. PubMed PMID: 12390554.

10. Wolpaw T, Papp KK, Bordage G. Using SNAPPS to facilitate the expression of clinical reasoning and uncertainties: a randomized comparison group trial. Acad Med. 2009;84(4):517-524. PubMed PMID: 19318792.

11. Wolpaw TM, Wolpaw DR, Papp KK. SNAPPS: a learner-centered model for out- patient education. Acad Med. 2003;78(9):893 898. PubMed PMID: 14507619

12. Cunningham AS, Blatt SD, Fuller PG, Weinberger HL. The art of precepting:Socrates or Aunt Minnie? Arch Pediatr Adolesc Med. 1999;153(2):114-116. PubMed PMID: 9988240.

13. Irby DM, Wilkerson L. Teaching when time is limited. BMJ. 2008;336(7640):384-387. Review. PubMed PMID: 18276715.

14. Dunn MM, Woolliscroft JO. Assessment of a pattern-recognition examination in a clinical clerkship. Acad Med. 1994;69(8):683. 684. PubMed PMID: 8054119.

15. Eva KW, Hatala RM, Leblanc VR, Brooks LR. Teaching from the clinical reason- ing literature: combined reasoning strategies help novice diagnosticians overcome misleading information. Med Educ. 2007;41(12):1152-1158.

16. Wilkerson L, Sarkin RT. Arrows in the quiver: evaluation of a workshop on ambulatory teaching. Acad Med. 1998;73(10 Suppl):S67-S69. PubMed PMID: 9795655. 